\title{
Comparative Evaluation of RNAlater Solution and Snap Frozen Methods for Gene Expression Studies in Different Tissues
}

\author{
Huseyin Ozkan ${ }^{1 *}$, Enes Kerman ${ }^{2}$ \\ 1. Hatay Mustafa Kemal University, Faculty of Veterinary Medicine, Dept. of Genetic, Hatay, Turkey \\ 2. Dept. of Forensic Clinic, Aydin Public Hospital, Aydın, Turkey
}

\begin{abstract}
Introduction: Freezing of tissues with liquid nitrogen is the most common method in studies performed at the RNA level. However, the use of RNA stabilization solutions has become a popular alternative method. The aim of this study is to investigate the effectiveness of RNAlater on RNA stabilization in different tissues. Material and Methods: In this study, RNA were isolated from the lung, heart, liver and skeletal muscle tissues of rats that were frozen with liquid nitrogen (snap frozen, SF group) or stored in RNAlater solution (RL group), and the changes in concentration, purity, reference genes expression, and fold-change levels between groups were analyzed. Results: In the RL group, the concentration of RNA isolated from the liver tissues was higher $(P<0.05)$, whereas the A260/280 ratio was lower in the heart and liver tissues $(P<0.05)$. PPIA and SRP72 genes were found to have lower Ct values in the heart tissues of rats in the RL group ( $P<0.05$ and $P<0.001$, respectively) than the SF group. Expression levels of PPIA, ACTB, and SRP72 genes across the tissues were found to be different between the groups $(P<0.05)$. The gene expression level examined in terms of fold-change was significantly different in the RL group (upregulated up to 4 folds and downregulated about 0.5 fold) $(P<0.05)$. Conclusions: The results showed that RNAlater can maintain the RNA integrity and can also change the results of gene expression because it does not inhibit biological activity. The snap freezing method is more reliable because gene expression is more stable in tissues frozen with liquid nitrogen.
\end{abstract}

Keywords: RNAlater, Snap Frozen, RNA Quality, Reference Gene, Gene Expression

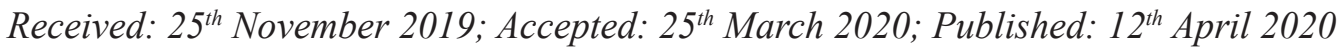

\section{Introduction}

RNA is an important intermediary molecule for understanding the molecular mechanisms of living things. RNA activity has been investigated at the level of transcription and translation by using RT-qPCR technology, particularly in gene expression studies in which physiological and pathological conditions are evaluated. In addition, the quality of RNA isolated from various tissues and cells is one of the most significant parameters that can affect the study outputs (1).

*Corresponding author: Huseyin Ozkan, Hatay Mustafa Kemal University, Faculty of Veterinary Medicine, Dept. of Genetic, Antakya/Hatay/Turkey. E-mail: hozkan@mku.edu.tr 
Therefore, particularly in studies performed at the mRNA level, the quality and integrity of RNA in target cells and/or tissues must be ensured and the tissues must be protected against temperature and various RNases (2).

To maintain the integrity of RNA in tissues, liquid nitrogen freezing immediately after the collection of tissues is commonly preferred. This method, which is also known as snap freezing method, is reliably used because it provides rapid RNase inactivation at a low temperature. However, there are some disadvantages in this process, such as the supply, transportation, and storage of liquid nitrogen $(3,4)$. As an alternative to the snap freezing method, various methods such as storage with formalin, paraffin, ethanol, and some storage solution for RNA stabilization like RNAlater RNAsafe have been reported. Some studies have shown that storage with these chemicals is not as efficient as snap freezing in terms of the maintenance of RNA quality (5-7). However, the use of RNAlater, an alternative method for preserving nucleic acids in tissues (particularly RNA), can maintain the quality of RNA (8). RNases are inactive when $\mathrm{pH}$ stabilization is ensured, owing to salts such as ammonium sulfate present in RNAlater-like chemicals; therefore, RNA quality can be maintained in stored tissues (9). In addition, RNAlater is recommended as an alternative to the snap freezing method because tissues stored with RNAlater can be kept at room temperature for up to 1 week, at $4^{\circ} \mathrm{C}$ for up to 1 month, and at $-80^{\circ} \mathrm{C}$ for longer periods $(4,5)$. RNA isolated from cells and tissues is evaluated in terms of quality, integrity, and purity parameters by electrophoretic and spectrophotometric methods. A260/280 ratio and $28 \mathrm{~S}$ and $18 \mathrm{~S}$ rRNA band integrity and ratios in total RNA are widely used, particularly in eukaryotic organisms (10, 11). In addition, there are various methods used for evaluating RNA integrity such as the calculation of total RNA amount, quantitation of tissues used in isolation, utilization of internal genes, and calculation of the RIN value. Expression levels of internal genes, particularly those used in relative gene expression studies, are more commonly preferred $(12,13)$.

Genes to be used as internal genes should be stable in the tissue and should not be affected by methodological procedures. Therefore, it is necessary to consider factors such as study hypothesis, organism, and tissue and cell type in the utilization of genes as an internal control that are called housekeeping or reference genes. However, numerous studies have reported that the reference gene to be internally used may be used as a reference in a particular tissue but may not be used in another tissue due to its tissue-dependent activity $(12,14)$. There are studies using standard methods (electrophoretic and spectrophotometric) to control the quality of RNA in tissues stored with RNAlater (15)ite $></$ EndNote $>$. Although there are some studies comparing the quantity of genes through Ct values by means of RT-qPCR in addition to standard controls, studies performing their examinations at the level of gene expression are limited $(15,16)$.

In this study, possible RNA quality loss that may occur in the lung, heart, liver, and skeletal muscle tissues stored in RNAlater was studied in terms of $\mathrm{Ct}$ and gene expression through electrophoretic and spectrophotometric controls as well as PPIA (Peptidylprolyl Isomerase A), ACTB (Beta Actin), GAPDH (Glyceraldehyde-3-Phosphate Dehydrogenase), and SRP72 (Signal Recognition Particle 72) genes, which are commonly used as reference genes (17-21).

\section{Materials and Methods}

\section{Animal Materials}

This study was approved by Hatay Mustafa Kemal University Animal Experiments Local Ethics Committee with a decision number 2018/9-3. In this study, six male wistar albino rats (10-week-old), weighing approximately 200 
$\mathrm{g}(202.22 \pm 14.67 \mathrm{~g})$, were used. The rats were maintained under standard conditions at Mustafa Kemal University Experimental Research and Application Center.

The ambient temperature and humidity were $21^{\circ} \mathrm{C} \pm 2^{\circ} \mathrm{C}$ and $55 \%$ respectively. The lighting schedule was a 12-12 h light-dark cycle (light period: $07.00-19.00 \mathrm{~h}$, dark period 19.00-07.00 h) during the study. The rats were maintained in polycarbonate transparent cages, each housing three rats, and were fed ad libitum with standard chow and water. At the end of the adaptation period, the rats were euthanized by exsanguination via cardiac puncture under anesthesia $(80 \mathrm{mg} / \mathrm{kg}$ ketamine and $12 \mathrm{mg} / \mathrm{kg}$ xylazine, IP).

The lung (right), heart (left ventricle), liver (right lobe), and skeletal muscle (left leg, $m$. gluteus) tissues were immediately collected from the rats and divided into two parts. One part was rapidly frozen with liquid nitrogen (snap frozen), while the other part was stored in RNAlater ${ }^{\circledR}$ (Cat No: AM7021, ThermoFisher Scientific, USA). The samples treated with RNAlater were kept in the RNAlater solution at an amount 10 times their weight in accordance with the kit usage guidelines. Samples frozen in liquid nitrogen (snap frozen group, SF group) were stored at $-86^{\circ} \mathrm{C}$. Samples submerged in RNAlater (RL group) solution were kept at $+4^{\circ} \mathrm{C}$ for one night to ensure the penetration of RNAlater in accordance with the kit usage guidelines and then stored at $-86^{\circ} \mathrm{C}$.

\section{RNA isolation and cDNA synthesis}

RNA was isolated using the Trizol method from samples stored at $-86^{\circ} \mathrm{C}$ in the $\mathrm{SF}$ and $\mathrm{RL}$ groups (22). In accordance with the kit protocol, $1 \mathrm{ml}$ Trizol (ThermoFisher Scientific, USA) was used per approximately $50 \mathrm{mg}$ tissue. Total RNA was extracted from samples after homogenization in Trizol under cold conditions, followed by chloroform, isopropyl alcohol, and ethyl alcohol treatments, and the samples were diluted with
30-100 $\mu \mathrm{L}$ nuclease-free water based on the pellet sizes. RNA concentration of the samples and purity measurements were performed using nucleic acid meter (Merinton SMA 1000, USA), and the quality of RNA was checked in 1\% agarose gel electrophoresis (100 V and $25 \mathrm{~min}$ ).

After DNase treatment with DNase I (DNase I, RNase free, ThermoFisher Scientific, Cat no: EN0525, USA), the isolated RNAs were converted to cDNA using High-Capacity cDNA Reverse Transcription Kit (ThermoFisher Scientific, Cat no: 4368814). cDNA was synthesized using $1000 \mu \mathrm{g}$ total RNA in Thermal cycler (Biorad $\mathrm{T} 100$, USA) at $25^{\circ} \mathrm{C}$ for $10 \mathrm{~min}, 37^{\circ} \mathrm{C}$ for 120 min, and $85^{\circ} \mathrm{C}$ for $5 \mathrm{~min}$, in accordance with the kit protocol. Following the reaction, the samples were made up to $200 \mu \mathrm{l}$ with nuclease-free water and stored at $-86^{\circ} \mathrm{C}$ until qPCR analysis.

\section{Quantitative Real Time PCR Analysis}

Amplification of the target genes was performed using $5 \mu$ of cDNA sample using the kit containing SYBR Green I dye (Power SYBR ${ }^{\circledR}$ Green PCR Master, ThermoFisher Scientific, USA, Cat no: 4367659), in accordance with the kit protocol. Each sample was duplicated. The reaction in qPCR (CFX96 Touch, Biorad, USA) was arranged using the following parameters: $10 \mathrm{~min}$ at $95^{\circ} \mathrm{C}$ and 40 cycles of $15 \mathrm{~s}$ at $95^{\circ} \mathrm{C}, 60 \mathrm{~s}$ at $60^{\circ} \mathrm{C}$. The PPIA primer sequences used in the study were obtained from the literature (23), and the primer sequences of $A C T B, G A P D H$, and $S R P 72$ genes were designed by the authors using Primer BLAST (NCBI) (Table 1). The area multiplied by each pair of primers was examined by melting curve analysis in $\mathrm{qPCR}$, and the PCR product was run on the $2 \%$ agarose gel, confirming that the primers were multiplied by one area.

\section{Statistical Analysis}

The differences between the tissues stored by the snap freezing and RNAlater methods were calculated using the SPSS program (Version 22.0). 
Table 1. Forward and Reverse Sequences of Genes Primers

\begin{tabular}{llcc}
\hline Gene & Accession No & Forward and Reverse Sequences & $\begin{array}{c}\text { Product Size } \\
\text { (bp) }\end{array}$ \\
\hline PPIA & \multirow{2}{*}{ NM_017101.1 } & $\begin{array}{r}\text { F: 5'-CAGACAAAGTTCCAAAGACAGCA-3' } \\
\text { R: 5'-CACCCTGGCACATGAATCCT-3' }\end{array}$ & 117 \\
\hline \multirow{2}{*}{ GAPDH } & NM_017008.4 & $\begin{array}{l}\text { F: 5'-AGTGCCAGCCTCGTCTCATA-3' } \\
\text { R: 5'-TCCCGTTGATGACCAGCTTC-3' }\end{array}$ & 234 \\
\hline \multirow{2}{*}{ ACTB } & NM_031144.3 & $\begin{array}{l}\text { F: 5'-GCAGGAGTACGATGAGTCCG-3' } \\
\text { R: 5'-ACGCAGCTCAGTAACAGTCC-3' }\end{array}$ & \multirow{2}{*}{74} \\
\hline \multirow{2}{*}{ SRP-72 } & NM_001170601.1 & F: 5'-ACCTGCCCTCATCGGATAGT-3' & 133 \\
\hline
\end{tabular}

The Ct levels differences between groups (SF vs RL) was analyzed by Student t-test. The difference among the tissues was determined with One Way Anova and later applicated by the Tukey test. The gene expression levels in the RL group relative to the SF group were calculated based on $2^{-\Delta \Delta \mathrm{Ct}}$ calculation method and were demonstrated as fold-change (24).

\section{Results}

The concentration and purity values of total RNA isolated from the lung, heart, liver, and skeletal muscle tissues in the SF and RL groups were determined to be appropriate for cDNA and $\mathrm{qPCR}$ applications. RNA concentration in the liver tissues was found to be significantly higher in the RL group. The A260/280 ratios in the heart and liver tissues were found to be lower in the RL group than in the SF group (Table 2).

RNA integrities were checked in $1 \%$ agarose gel electrophoresis. RNA samples $28 \mathrm{~S}$ and $18 \mathrm{~S}$ rRNA subunits pictures were given in figure 1 .

There was no significant difference between the groups in terms of Ct values of PPIA, GAPDH, and SRP72 genes in the lung, liver, and skeletal muscle tissues (Table 3). However, the $\mathrm{Ct}$ values of PPIA and SRP72 genes were found to be approximately $1.5 \mathrm{Ct}$ higher in the heart tissues in the SF group. The Ct value of $A C T B$ gene in the skeletal muscle tissues in the RL group was approximately $2 \mathrm{Ct}$ higher than those in the SF group.

The highest $\mathrm{Ct}$ values for PPIA genes in both groups were found in the skeletal muscle tissues; in other words, this gene has the lowest expression level in the skeletal muscle among the other studied tissues. The highest $A C T B$ gene expression was found in the lung tissue $(P<0.001)$. There was no significant difference between the tissues in terms of GAPDH expression levels. The lowest SRP72 gene expression was determined in the skeletal muscle and heart tissue in the SF group and skeletal muscle in the RL group (Table 3 ).

The genes used in the study were used both as reference and target genes in all tissues, and

Table 2. Concentrations and A260/280 ratios of RNA samples in Tissues ( $\bar{X} \pm S \bar{x})$

\begin{tabular}{lcccccc}
\hline \multirow{2}{*}{ Tissue } & \multicolumn{2}{c}{ Concentration $(\mathbf{n g} / \boldsymbol{\mu L})$} & \multicolumn{3}{c}{ A260/A280 ratio } \\
\cline { 2 - 7 } & SF Group & RL Group & P & SF Group & RL Group & P \\
\hline Lung & $246.52 \pm 39.61$ & $356.01 \pm 63.66$ & - & $1.74 \pm 0.02$ & $1.77 \pm 0.02$ & - \\
\hline Heart & $767.34 \pm 72.98$ & $291.73 \pm 85.92$ & - & $1.86 \pm 0.08$ & $1.77 \pm 0.02$ & $<0.05$ \\
\hline Liver & $216.09 \pm 27.24$ & $624.58 \pm 113.28$ & $<0.05$ & $1.86 \pm 0.75$ & $1.77 \pm 0.19$ & $<0.05$ \\
\hline S. Muscle & $300.06 \pm 38.43$ & $334.87 \pm 88.94$ & - & $1.95 \pm 0.09$ & $1.84 \pm 0.05$ & - \\
\hline
\end{tabular}

SF: Snap frozen; RL: RNAlater; S. Muscle: Skeletal Muscle; -: P $>0.05$; X \pm Sx: Average \pm Standard Error 



Fig. 1. rRNA bands of RNA samples in tissues in SF and RL groups. a) Lung tissue RNA samples in SF group, b) Lung tissue RNA samples in RL group, c) Heart tissue RNA samples in SF group, d) Heart tissue RNA samples in RL group, e) Liver tissue RNA samples in SF group, f) Liver tissue RNA samples in RL group, g) Skeletal Muscle RNA samples in SF group, h) Skeletal Muscle RNA samples in RL group.

Table 3. Averages of Ct Values in Different Tissues stored with different methods $(\bar{x} \pm S \bar{x})$

\begin{tabular}{|c|c|c|c|c|c|c|}
\hline \multirow[b]{2}{*}{ Genes } & \multirow[b]{2}{*}{ Groups } & \multicolumn{4}{|c|}{ Tissues } & \multirow[b]{2}{*}{$P$} \\
\hline & & Lung & Heart & Liver & S. Muscle & \\
\hline \multirow{3}{*}{ PPIA } & SF & $17.37 \pm 0.28^{\mathrm{b}}$ & $19.89 \pm 0.13^{\mathrm{a}}$ & $16.85 \pm 0.15^{\mathrm{b}}$ & $20.66 \pm 1.07^{\mathrm{a}}$ & $<0.001$ \\
\hline & RL & $16.67 \pm 0.61^{\mathrm{b}}$ & $18.46 \pm 0.50^{\mathrm{b}}$ & $17.78 \pm 0.48^{b}$ & $21.03 \pm 0.91^{\mathrm{a}}$ & $<0.001$ \\
\hline & $\mathbf{P}$ & - & $<0.05$ & - & - & \\
\hline \multirow{3}{*}{ ACTB } & SF & $15.31 \pm 0.17^{\mathrm{c}}$ & $19.52 \pm 0.23^{\mathrm{a}}$ & $18.33 \pm 0.16^{\mathrm{b}}$ & $18.83 \pm 0.27^{\mathrm{a}, \mathrm{b}}$ & $<0.001$ \\
\hline & RL & $15.77 \pm 0.70^{\mathrm{b}}$ & $19.84 \pm 0.89^{\mathrm{a}}$ & $19.35 \pm 0.43^{\mathrm{a}}$ & $21.11 \pm 0.28^{\mathrm{a}}$ & $<0.001$ \\
\hline & $\mathbf{P}$ & - & - & - & $<0.001$ & \\
\hline \multirow{3}{*}{ GAPDH } & SF & $18.40 \pm 0.32$ & $17.86 \pm 0.23$ & $17.08 \pm 0.22$ & $16.83 \pm 1.41$ & - \\
\hline & RL & $18.35 \pm 1.13$ & $16.63 \pm 0.65$ & $17.44 \pm 0.39$ & $20.42 \pm 2.20$ & - \\
\hline & $\mathbf{P}$ & - & - & - & - & \\
\hline \multirow{3}{*}{ SRP72 } & SF & $21.10 \pm 0.31^{\mathrm{b}}$ & $23.60 \pm 0.20^{\mathrm{a}}$ & $21.14 \pm 0.15^{\mathrm{b}}$ & $23.72 \pm 1.28^{\mathrm{a}}$ & $<0.05$ \\
\hline & RL & $21.41 \pm 0.76^{\mathrm{b}}$ & $21.91 \pm 0.15^{\mathrm{b}}$ & $21.50 \pm 0.45^{\mathrm{b}}$ & $25.41 \pm 1.17^{\mathrm{a}}$ & $<0.01$ \\
\hline & $\mathbf{P}$ & - & $<0.001$ & - & - & \\
\hline
\end{tabular}

SF: Snap Fozen; RL: RNAlater; -: $P>0.05 ;$ a, b, c: Means with different letters in rows differ significantly; $\mathrm{X} \pm$ Sx: Average \pm Standard Error 
Table 4. Fold Changes of Genes in Lung, Heart, Liver, and Skeletal Muscle ( $\overline{\mathrm{X}} \pm \mathrm{S} \overline{\mathrm{x}})$

\begin{tabular}{lccccc}
\hline Genes & & Lung & Heart & Liver & S. Muscle \\
\hline REFERENCE & TARGET & SF vs RL & SF vs RL & SF vs RL & SF vs RL \\
\hline PPIA & ACTB & $2.36 \pm 0.97^{*}$ & $3.94 \pm 0.87^{*}$ & $1.14 \pm 0.27$ & $3.30 \pm 0.83^{*}$ \\
\cline { 2 - 5 } & GAPDH & $2.38 \pm 1.07$ & $1.27 \pm 0.25$ & $1.05 \pm 0.36$ & $53.97 \pm 40.13$ \\
\cline { 2 - 5 } & SRP72 & $2.06 \pm 0.24^{*}$ & $1.01 \pm 0.28$ & $1.00 \pm 0.32$ & $2.53 \pm 0.52^{*}$ \\
\cline { 2 - 5 } ACTB & PPIA & $0.48 \pm 0.08^{* *}$ & $0.35 \pm 0.08^{* * *}$ & $0.99 \pm 0.16$ & $0.15 \pm 0.07$ \\
\cline { 2 - 5 } & GAPDH & $1.01 \pm 0.47$ & $0.42 \pm 0.14^{* *}$ & $0.72 \pm 0.16$ & $13.94 \pm 11.69$ \\
\hline GAPDH & SRP72 & $0.91 \pm 0.12$ & $0.44 \pm 0.16^{*}$ & $0.77 \pm 0.20$ & $0.35 \pm 0.21$ \\
& ACTB & $1.66 \pm 0.29$ & $3.41 \pm 0.66^{* *}$ & $1.83 \pm 0.50$ & $1.21 \pm 0.53$ \\
\hline \multirow{2}{*}{ SRP72 } & PPIA & $0.83 \pm 0.34$ & $0.97 \pm 0.21$ & $2.38 \pm 0.88$ & $0.34 \pm 0.15^{*}$ \\
& SRP72 & $1.43 \pm 0.240$ & $0.94 \pm 0.30$ & $1.03 \pm 0.14$ & $0.62 \pm 0.25$ \\
& ACTB & $1.11 \pm 0.15$ & $7.20 \pm 2.66$ & $1.90 \pm 0.48$ & $1.59 \pm 0.53$ \\
\cline { 2 - 5 } & GAPDH & $0.95 \pm 0.32$ & $1.71 \pm 0.46$ & $1.01 \pm 0.13$ & $13.16 \pm 8.83$ \\
\cline { 2 - 5 } & PPIA & $0.51 \pm 0.06^{* *}$ & $1.44 \pm 0.36$ & $2.30 \pm 0.83$ & $0.40 \pm 0.09^{*}$ \\
\hline
\end{tabular}

*: $\mathrm{P}<0.05 ; * *: \mathrm{P}<0.01 ; * * *: \mathrm{P}<0.001 ; \mathrm{X} \pm \mathrm{Sx}:$ Average \pm Standard Error

the fold-change values were calculated. When $P P I A$ was considered as a reference gene, the expression level of $A C T B$ and SRP72 genes in the lung and skeletal muscle tissues in the RL group was 2 folds higher than that in the SF group $(P<0.05)$. In addition, the expression level of $A C T B$ gene in the heart tissues in the RL group was approximately 4 folds higher than that in the SF group. When ACTB is considered as a reference gene, the expression levels of PPIA, GAPDH, and SRP72 genes in the heart tissues and of only PPIA in the lung tissues were found to be downregulated (fold-change values $<0.50 ; P<0.05)$. When $G A P D H$ is considered as a reference gene, it was found that ACTB gene was approximately 4 folds upregulated in the heart tissues $(P<0.01)$, whereas PPIA gene was downregulated (fold-change $=0.337 \pm 0.148$; $P<0.05)$. When $S R P 72$ was considered as a reference gene, PPIA was found to be downregulated in the lung and skeletal muscle tissues $(P<0.05)$ (Table 4).

\section{Discussion}

In quality control of RNA isolated from cells and tissues, the expression levels of reference genes used for internal control have been examined by methods in which various parameters such as RNA concentration and purity and $28 \mathrm{~S}$ and $18 \mathrm{~S}$ band integrity ratios $(8,12,25,26)$. There must be no contamination and degradation in RNA isolated from tissues to be studied under normal conditions. RNA quality is deteriorated due to storage conditions following the collection of tissues, and low-quality RNA leads to different results in gene expression studies performed with qPCR $(13,27)$.

In this study, RNA was examined in tissues stored with snap freezing and RNAlater methods in terms of purity, concentration, and integrity. The samples in both groups qualified for cDNA conversion based on the A260/280 ratio, concentration values, and $28 \mathrm{~S}$ and $18 \mathrm{~S}$ band ratio. In addition, the concentration levels in liver samples of the RL group were higher than those of the SF group, whereas the A260/280 ratios were lower $(P<0.05)$. The A260/280 ratios in the heart tissues in the RL group were found to be lower than those in the SF group $(P<0.05)$.

In addition, the concentration required for the various cDNA kits used in gene expression studies can be achieved with the samples obtained in both groups (such as High-Capacity cDNA Re- 
verse Transcription Kit, RevertAid First Strand cDNA Synthesis Kit, ThermoFisher Scientific, and iScript cDNA synthesis kit, Biorad). If the A260/280 ratios, which give an idea about the purity of isolated RNAs, are $\geq 1.7$, they are appropriate for gene expression studies $(11,28)$. However, some studies have reported that it is not possible to have sufficient knowledge about RNA quality by checking the integrity of rRNA bands (29-31). In this study, lung tissue rRNA bands qualities were the same in both groups (SF and RL groups). On the other hand, in RL group, heart, liver and skeletal muscle RNA samples were looking worse than SF group. RNA qualities in all tissues have enough quality with snap freezing method (Figure 1).

There was a statistically significant difference between the SF and RL groups in terms of Ct values of PPIA and SRP72 genes in the heart tissues $(P<0.05$ and $P<0.001$, respectively). The Ct values of these genes were found to be lower in the heart tissues in the RL group (Table 3). In their study on the efficiency of RNAlater, Martin et al. (32) have examined the expression levels of some reference genes in placental tissues and reported that $\mathrm{Ct}$ values of these genes were significantly lower. Although in the light of these data, they reported that the storage with RNAlater could result in RNAs of better quality, protein activity varies across the tissues due to differences in the gene activity and perfusion rate $(19,33)$.

Higher $\mathrm{Ct}$ values in the tissues stored with different methods than those obtained via the snap freezing method have been associated with low RNA quality $(34,35)$. Although RNAlater contributes to the prevention of RNA degradation by limiting the RNase activity, its effect on gene activity is not exactly known when the tissues are stored in RNAlater at $+4^{\circ} \mathrm{C}$. A study has reported that when tissues are stored in the RNAlater, there were increases or decreases in the activity of about 3,000 genes (15). This may be caused by the fact that gene activity is not inhibited during fixation of tissues with RNAlater.

The lack of a difference between the groups in terms of $\mathrm{Ct}$ values of $A C T B$ and $G A P D H$ genes in the heart tissue in addition to the groups being similar in terms of other genes suggests that RNAlater does not exert similar effects in all tissues. The fact that the expression level of $A C T B$ gene in the muscle tissue was higher in the SF group (approximately $2 \mathrm{Ct}$ higher in the RL group, $P<0.001)$ is an indication of this suggestion (Table 3).

In both groups, the highest expression level for the ACTB gene expression, which is of the reference genes, was observed in the lung tissue (Table 3). The lowest SRP72 gene expression was observed in the skeletal muscle tissue (Figure 1). Although expression level of a particular gene provides an idea about its utility as a reference gene in the relevant tissue, Hruz et al. (36) and Sampaio-Silva et al. (37) have reported that $S R P 72$ gene could be reliably used as a reference gene in skeletal muscle tissues.

It is known that RNA quality is low if it is isolated from formalin-fixed and paraffin-embedded tissues as an alternative to the snap freezing method (38). In a study comparing formalin-fixed and snap frozen tissues, it was reported that $\mathrm{Ct}$ values were lower in snap frozen samples and increased in formalin-fixed samples (35). If this increase is up to 128 times higher as reported in the study by Viertler et al. (35), it can provide incorrect outputs in the gene expression studies since it can result in significant errors in the calculation of expression levels. On the contrary, in a study that emphasized the importance of RNA quality in microarray studies, RNAlater and snap freezing methods were compared using breast tumor tissues, and a high concentration of RNA was obtained from the tissues stored in RNAlater, similar to RNA concentration levels in the liver tissues. In the same study, the RNA integrity was also reported to be better (39). In 
this study, although no significant differences were found in the concentration, purity and $\mathrm{Ct}$ values of different tissues, there were significant changes in the gene expression level (Table 3 ). In a study performed on the storage of rat livers (5), the band integrity was reported to be better in liver samples stored in RNAlater solution for different time periods and at different temperatures than those stored at $-80^{\circ} \mathrm{C}$ and those stored at $-80^{\circ} \mathrm{C}$ after freezing with liquid nitrogen (5). Another study comparing snap freezing method and directly freezing at $-80^{\circ} \mathrm{C}$ reported that snap freezing method allows isolation of higher quality RNAs from liver tissues (3).

In studies using RNAlater solution to examine $\mathrm{Ct}$ values of some reference genes by qPCR and to evaluate RNA quality using electrophoretic and spectrophotometric methods, this chemical has been reported to maintain the stability of RNA $(4,5,9,40)$. The use of internal gene is one of the important methods used to control the RNA quality (25). In this study, unlike other studies, the expression levels of PPIA, ACTB, $G A P D H$, and SRP72 genes, which are used as internal genes, were calculated as fold-change and compared between the SF and RL groups. When the genes studied in terms of $\mathrm{Ct}$ levels were considered as reference gene and the foldchange in other genes is calculated based on the $2^{-\Delta \Delta C t}$ method, it was observed that there were significant changes in the RL group. In lung, heart muscle and skeletal muscle tissues, upregulation up to 4 times or downregulation less than 0.5 times was observed in terms of $A C T B, P P I A$ and SRP72 (Table 4, $P<0.05$ ). This is one of the most significant indicators that the storage with snap freezing method is more reliable than the RNAlater method. In the examination of expression level, there was no statistically significant difference between both methods in terms of fold-change in the liver tissues. This shows the importance of tissue selection both in the selec- tion of reference gene as well as in studies to be performed on the RNA quality. Liver is a tissue in which the metabolic activity is most intense. Considering this, the RNase activity is expected to be high (41). On the other hand, GAPDH gene expression levels showed that it is not a reliable gene for internal control in skleletal muscle which stored in RNAlater (Table 4). Although the RNAlater inactivates the RNases, a certain level of RNase activity causes degradation and leads to decreased gene expression.

In the study, the molecular effects of snap frozen and RNAlater methods were investigated in different tissues of rats. However, unlike similar studies, biological activity in more than one tissue was investigated by calculating at the level of gene expression. As a result of the findings and the literature searches, it is thought that RNAlater has changeable efficacies for maintaining RNA stabilization. In this study, only 4 different tissues in 6 animals were evaluated. Considering the material and methodology of this study, it can be said that Snap frozen method is better than RNAlater for gene expression studies.

\section{Conclusion}

With technological advances, experimental studies at the RNA level have become widespread in many areas. This leads to the emergence of alternative methods for the storage of tissues to be studied for gene expression calculations. With this study, it may be represented that the storage with RNAlater solution, which is one of these methods, is not as reliable as the snap freezing method. In conclusion, it is considered that more studies with more animal numbers is needed and the content of this chemical can be further improved, considering its unknown effects on mRNA fragments of different sizes in total RNA and on the inhibition of physiological activity. 


\author{
Abbreviations \\ ACTB, Beta Actin \\ GAPDH, Glyceraldehyde-3-Phosphate Dehy- \\ drogenase \\ PPIA, Peptidylprolyl Isomerase A \\ RL, RNAlater \\ SF, Snap Frozen \\ SRP72, Signal Recognition Particle 72
}

\section{Acknowledgement}

This research did not receive any specific grant from funding agencies in the public, commercial, or not-for-profit sectors.

\section{Authors' contribution}

HO (Conceptualization; Data curation; Formal analysis; Investigation; Methodology; Writing original draft; Writing - review \& editing)

EK (Methodology; Writing - original draft)

\section{Conflict of Interest}

The authors declare no conflict of interest.

\section{References}

1. Pérez-Novo CA, Claeys C, Speleman F, Van Cauwenberge P, Bachert C, Vandesompele J. Impact of RNA quality on reference gene expression stability. BioTechniques. 2005;39(1):52-6. DOI: 10.2144/05391BM05

2. González-Herrera L, Valenzuela A, Marchal JA, Lorente JA, Villanueva E. Studies on RNA integrity and gene expression in human myocardial tissue, pericardial fluid and blood, and its postmortem stability. Forensic Sci Int. 2013;232(1-3):218-28. DOI: 10.1016/j. forsciint.2013.08.001

3. Özkan H, Yakan A. RNA Quality in Snap and Directly $-80^{\circ} \mathrm{C}$ Frozen Liver Tissues. Lalahan Hay Araşt Enst Derg. 2018;58(1): 42-7.

4. Mohammad Najafi ZS. RNA Preservation and Stabilization. Biochem Physiol. 2014;3(1):1-4. DOI: 10.4172/2168-9652.1000126

5. Kasahara T, Miyazaki T, Nitta H, Ono A, Miyagishima T, Nagao T, et al. Evaluation of methods for duration of preservation of RNA quality in Rat liver used for tran- scriptome analysis. J Toxicol Sci. 2006;31(5):509-19. DOI: $10.2131 /$ jts.31.509

6. Esteve-Codina A, Arpi O, Martinez-Garca M, Pineda E, Mallo M, Gut M, et al. A Comparison of RNA-Seq Results from Paired Formalin-Fixed Paraffin-Embedded and Fresh-Frozen Glioblastoma Tissue Samples. PloS one. 2017;12(1):1-18. DOI: 10.1371/journal. pone. 0170632

7. Wang SS, Sherman ME, Rader JS, Carreon J, Schiffman M, Baker CC. Cervical tissue collection methods for RNA preservation: comparison of snap-frozen, ethanol-fixed, and RNAlater-fixation. Diagn mol pathol. 2006;15(3):144-8. DOI: 10.1097/01. pdm.0000213460.53021.cd

8. Wang Y, Zheng H, Chen J, Zhong X, Wang Y, Wang Z, et al. The Impact of Different Preservation Conditions and Freezing-Thawing Cycles on Quality of RNA, DNA, and Proteins in Cancer Tissue. Biopreserv Biobank. 2015;13(5):335-47. DOI: 10.1089/bio.2015.0029

9. Arnold PR, Lord NP, Smith AN, Bybee SM. The Effects of Non-Ideal Temperature Regimes on RNA Quality from Samples Stored in RNAlater-like Buffer: An Attempt to Replicate Field Conditions. J Analyt Molecul Tech. 2016;2(1):1-8. DOI: 10.13188/24741914.1000006

10. Kirchner B, Paul V, Riedmaier I, Pfaffl MW. mRNA and microRNA Purity and Integrity: The Key to Success in Expression Profiling. Methods Mol Biol. 2014; 43-53. DOI: 10.1007/978-1-4939-0733-5_5

11. Bustin SA, Benes V, Garson JA, Hellemans J, Huggett J, Kubista M, et al. The MIQE Guidelines: Minimum Information for Publication of Quantitative Real-Time PCR Experiments. Clin Chem. 2009;55(4):611-22. DOI: $10.1373 /$ clinchem.2008.112797

12. Koppelkamm A, Vennemann B, Fracasso T, Lutz-Bonengel S, Schmidt U, Heinrich M. Validation of adequate endogenous reference genes for the normalisation of qPCR gene expression data in human post mortem tissue. Int J Legal Med. 2010;124(5):371-80. DOI: $10.1007 / \mathrm{s} 00414-010-0433-9$

13. McIntosh CH, Baird J, Zinser E, Woods DJ, Campbell EM, Bowman AS. Reference gene selection and RNA preservation protocol in the cat flea, Ctenocephalides felis, for gene expression studies. Parasitology. 2016;143(12):1532-42. DOI: 10.1017/ S0031182016001025

14. Radonić A, Thulke S, Mackay IM, Landt O, Siegert 
W, Nitsche A. Guideline to reference gene selection for quantitative real-time PCR. Biochem Biophys Res Commun. 2004;313(4):856-62. DOI: 10.1016/j. bbrc.2003.11.177

15. Passow CN, Kono TJY, Stahl BA, Jaggard JB, Keene AC, McGaugh SE. RNAlater and flash freezing storage methods nonrandomly influence observed gene expression in RNAseq experiments. bioRxiv. 2018; 1-15. DOI: $10.1101 / 379834$

16. Gonzlez-Herrera L, Valenzuela A, Marchal JA, Lorente JA, Villanueva E. Studies on RNA integrity and gene expression in human myocardial tissue, pericardial fluid and blood, and its postmortem stability. Forensic Sci Int. 2013;232(1-3):218-28. DOI: 10.1016/j.forsciint.2013.08.001

17. Tu C, Du T, Shao C, Liu Z, Li L, Shen Y. Evaluating the potential of housekeeping genes, rRNAs, snRNAs, microRNAs and circRNAs as reference genes for the estimation of PMI. Forensic Sci Med Pathol. 2018;14(2):194-201. DOI: 10.1007/s12024-0189973-y

18. Eisenberg E, Levanon EY. Human housekeeping genes, revisited. Trends Genet. 2013;29(10):569-74. DOI: 10.1016/j.tig.2013.05.010

19. Stürzenbaum SR, Kille P. Control genes in quantitative molecular biological techniques: The variability of invariance. Comp Biochem Physiol B Biochem Mol Biol. 2001;130(3):281-9. DOI: 10.1016/S10964959(01)00440-7

20. de Jonge HJM, Fehrmann RSN, de Bont ESJM, Hofstra RMW, Gerbens F, Kamps WA, et al. Evidence Based Selection of Housekeeping Genes. PLoS ONE. 2007;2(9):1-5. DOI: 10.1371/journal.pone.0000898

21. Synnergren J, Giesler TL, Adak S, Tandon R, Noaksson $\mathrm{K}$, Lindahl A, et al. Differentiating human embryonic stem cells express a unique housekeeping gene signature. Stem cells. 2007;25(2):473-80. DOI: 10.1634/ stemcells.2006-0247

22. Rio DC, Ares M, Hannon GJ, Nilsen TW. Purification of RNA using TRIzol (TRI Reagent). Cold Spring Harb Protocols. 2010;5(6):1-4. DOI: 10.1101/pdb.prot5439

23. dos Santos BP, da Costa Diesel LF, da Silva Meirelles L, Nardi NB, Camassola M. Identification of suitable reference genes for quantitative gene expression analysis in rat adipose stromal cells induced to trilineage differentiation. Gene. 2016;594(2):211-9. DOI: 10.1016/j. gene.2016.09.002
24. Livak KJ, Schmittgen TD. Analysis of Relative Gene Expression Data Using Real-Time Quantitative PCR and the $2-\Delta \Delta C$ T Method. Methods. 2001;25(4):402-8. DOI: $10.1006 /$ meth.2001.1262

25. Sun J-h, Nan L-h, Gao C-r, Wang Y-y. Validation of reference genes for estimating wound age in contused rat skeletal muscle by quantitative real-time PCR. International J Leg Med. 2012;126(1):113-20. DOI: 10.1007/ s00414-011-0604-3

26. Li J, Smyth P, Flavin R, Cahill S, Denning K, Aherne $\mathrm{S}$, et al. Comparison of miRNA expression patterns using total RNA extracted from matched samples of formalin-fixed paraffin-embedded (FFPE) cells and snap frozen cells. BMC Biotechnol. 2007;7(1):36-42. DOI: 10.1186/1472-6750-7-36

27. Fleige S, Pfaffl MW. RNA integrity and the effect on the real-time qRT-PCR performance. Mol Aspects Med. 2006;27(2-3):126-39. DOI: 10.1016/j. mam.2005.12.003

28. Nolan T, Hands RE, Bustin SA. Quantification of mRNA using real-time RT-PCR. Nat Protoc. 2006;1(3):155982. DOI: $10.1038 /$ nprot.2006.236

29. Miller CL, Diglisic S, Leister F, Webster M, Yolken RH. Evaluating RNA status for RT-PCR in extracts of postmortem human brain tissue. BioTechniques. 2004;36(4):628-33. DOI: 10.2144/04364ST03

30. Imbeaud S. Towards standardization of RNA quality assessment using user-independent classifiers of microcapillary electrophoresis traces. Nucleic Acids Res. 2005;33(6):56-68. DOI: 10.1093/nar/gni054

31. Kono N, Nakamura H, Ito Y, Tomita M, Arakawa K. Evaluation of the impact of RNA preservation methods of spiders for de novo transcriptome assembly. Mol Ecol Resour. 2016;16(3):662-72. DOI: 10.1111/17550998.12485

32. Martin NM, Cooke KM, Radford CC, Perley LE, Silasi M, Flannery CA. Time course analysis of RNA quality in placenta preserved by RNA later or flash freezing. Am J Reprod Immunol. 2017;77(4):1-5. DOI: 10.1111/ aji. 12637

33. Thellin O, Zorzi W, Lakaye B, De Borman B, Coumans B, Hennen $G$, et al. Housekeeping genes as internal standards: use and limits. J Biotechnol. 1999;75(23):291-5. DOI: 10.1016/S0168-1656(99)00163-7

34. Martin NM, Cooke KM, Radford CC, Perley LE, Silasi M, Flannery CA. Time course analysis of RNA quality in placenta preserved by RNAlater or flash freezing. 
Am J Reprod Immunol. 2017;77(4):1-5. DOI: 10.1111/ aji. 12637

35. Viertler C, Groelz D, Gündisch S, Kashofer K, Reischauer B, Riegman PHJ, et al. A New Technology for Stabilization of Biomolecules in Tissues for Combined Histological and Molecular Analyses. J Mol Diagn. 2012;14(5):458-66. DOI: 10.1016/j. jmoldx.2012.05.002

36. Hruz T, Wyss M, Docquier M, Pfaffl MW, Masanetz S, Borghi L, et al. RefGenes: identification of reliable and condition specific reference genes for RT-qPCR data normalization. BMC Genomics. 2011;12(1):156-170. DOI: 10.1186/1471-2164-12-156

37. Sampaio-Silva F, Magalhes T, Carvalho F, Dinis-Oliveira RJ, Silvestre R. Profiling of RNA degradation for estimation of post mortem corrected interval. PloS one. 2013;8(2):1-8. DOI: 10.1371/journal.pone.0056507

38. Evers DL, Fowler CB, Cunningham BR, Mason JT,
O'Leary TJ. The Effect of Formaldehyde Fixation on RNA. J Mol Diagn. 2011;13(3):282-8. DOI: 10.1016/j. jmoldx.2011.01.010

39. Hatzis C, Sun H, Yao H, Hubbard RE, Meric-Bernstam F, Babiera GV, et al. Effects of Tissue Handling on RNA Integrity and Microarray Measurements From Resected Breast Cancers. J Natl Cancer Inst. 2011;103(24):187183. DOI: $10.1093 /$ jnci/djr438

40. Mutter GL, Zahrieh D, Liu C, Neuberg D, Finkelstein D, Baker HE, et al. Comparison of frozen and RNALater solid tissue storage methods for use in RNA expression microarrays. BMC genomics. 2004;5:88-95. DOI: 10.1186/1471-2164-5-88

41. Uhlén M, Fagerberg L, Hallström BM, Lindskog C, Oksvold P, Mardinoglu A, et al. Tissue-based map of the human proteome. Science. 2015;347(6220):1-11. DOI: $10.1126 /$ science. 1260419 